Article

\title{
Investigation of Lithium Ion Diffusion of Graphite Anode by the Galvanostatic Intermittent Titration Technique
}

\author{
Jong Hyun Park ${ }^{1}$, Hana Yoon ${ }^{1}$, Younghyun $\mathrm{Cho}^{2}$ and Chung-Yul Yoo ${ }^{3, *(\mathbb{D}}$ \\ 1 Energy Conversion \& Storage Materials Research Laboratory, Korea Institute of Energy Research, \\ 152 Gajeong-ro, Yuseong-gu, Daejeon 34129, Korea; whdgus615@gmail.com (J.H.P.); \\ hanayoon@kier.re.kr (H.Y.) \\ 2 Department of Energy Systems Engineering, Soonchunhyang University, Asan 31538, Korea; yhcho@sch.ac.kr \\ 3 Department of Chemistry, Mokpo National University, Muan-gun 58554, Korea \\ * Correspondence: chungyulyoo@mokpo.ac.kr; Tel.: +82-61-450-2335
}

Citation: Park, J.H.; Yoon, H.; Cho, Y.; Yoo, C.-Y. Investigation of Lithium Ion Diffusion of Graphite Anode by the Galvanostatic Intermittent Titration Technique. Materials 2021, 14, 4683.

https://doi.org/10.3390/ ma14164683

Academic Editor: Cai Shen

Received: 28 June 2021

Accepted: 18 August 2021

Published: 19 August 2021

Publisher's Note: MDPI stays neutral with regard to jurisdictional claims in published maps and institutional affiliations.

Copyright: (c) 2021 by the authors. Licensee MDPI, Basel, Switzerland. This article is an open access article distributed under the terms and conditions of the Creative Commons Attribution (CC BY) license (https:// creativecommons.org/licenses/by/ $4.0 /)$.

\begin{abstract}
Graphite is used as a state-of-the-art anode in commercial lithium-ion batteries (LIBs) due to its highly reversible lithium-ion storage capability and low electrode potential. However, graphite anodes exhibit sluggish diffusion kinetics for lithium-ion intercalation/deintercalation, thus limiting the rate capability of commercial LIBs. In order to determine the lithium-ion diffusion coefficient of commercial graphite anodes, we employed a galvanostatic intermittent titration technique (GITT) to quantify the quasi-equilibrium open circuit potential and diffusion coefficient as a function of lithium-ion concentration and potential for a commercial graphite electrode. Three plateaus are observed in the quasi-equilibrium open circuit potential curves, which are indicative of a mixed phase upon lithium-ion intercalation/deintercalation. The obtained diffusion coefficients tend to increase with increasing lithium concentration and exhibit an insignificant difference between charge and discharge conditions. This study reveals that the diffusion coefficient of graphite obtained with the GITT $\left(1 \times 10^{-11} \mathrm{~cm}^{2} / \mathrm{s}\right.$ to $\left.4 \times 10^{-10} \mathrm{~cm}^{2} / \mathrm{s}\right)$ is in reasonable agreement with literature values obtained from electrochemical impedance spectroscopy. The GITT is comparatively simple and direct and therefore enables systematic measurements of ion intercalation/deintercalation diffusion coefficients for secondary ion battery materials.
\end{abstract}

Keywords: graphite; diffusion coefficient; galvanostatic intermittent titration technique; quasiequilibrium open circuit potential; lithium-ion battery

\section{Introduction}

Over the last three decades, lithium-ion batteries (LIBs) have been employed for diverse energy storage applications ranging from portable electronics to stationary energy storage systems [1,2]. The performance of LIBs is determined by lithium-ion diffusion in both the anode and cathode, which is furthermore coupled to electron transport [3]. For the practical use of electrodes, the lithium-ion diffusion coefficient of an electrode can be used as a performance descriptor [4-7].

It is generally recognized that graphite anodes limit the rate capability of commercial LIBs due to slow lithium-ion diffusion, allowing only a rate of up to $1 \mathrm{C}$ for the charging process in order to prevent lithium metal plating on the graphite surface in fast charge regimes [3]. The lithium-ion diffusion coefficient of graphite has been reported across seven orders of magnitude (from $10^{-12}$ to $10^{-5} \mathrm{~cm}^{2} / \mathrm{s}$ ), as determined from electrochemical impedance spectroscopy (EIS) [8-14], galvanostatic intermittent titrations [15,16], and potentiostatic intermittent titrations $[17,18]$. EIS is a useful tool for identifying the contribution of different charge transfer and transport processes to overall electrochemical cell impedance $[19,20]$. EIS with subsequent equivalent circuit model fitting has been widely used to determine the diffusion coefficient of graphite [8-14]. However, diffusion coefficients measured by EIS are sensitive to differences in particle size and shape of the electrode 
materials [21], resulting in seemingly disparate diffusion coefficients in the literature. Conversely, the galvanostatic intermittent titration technique (GITT) is insensitive to particle size and electrode shape, which allows both thermodynamic and kinetic parameters to be determined, including the lithium-ion diffusion coefficient [21]. GITT measurements are composed of a series of small positive (or negative) current pulses followed by a relaxation period, where no current passes through the cell. This allows for the quasi-equilibrium open circuit voltage (open circuit voltage as a function of the state of charge) to be obtained as a function of intercalated ion concentration. Furthermore, the diffusion coefficient can be extracted by monitoring the change in potential with time under the assumption of Fick's law. Despite there being various reports on graphite analysis using EIS and the GITT, there are few detailed studies that use the GITT to evaluate the diffusion coefficient of graphite as a function of lithium-ion concentration and potential.

In this study, we prepared a coin cell using a commercial graphite electrode sheet as the counter electrode and lithium metal as the reference electrode. The charge-discharge behavior of the coin cell was performed as a function of charge rate, confirming reversible lithium-ion intercalation/deintercalation below 0.2C. GITT experiments were performed with three different $\mathrm{C}$-rates (i.e., $0.2 \mathrm{C}, 0.05 \mathrm{C}$, and $0.01 \mathrm{C}$ ), revealing that $0.05 \mathrm{C}$ is the optimum condition for extracting the quasi-equilibrium open circuit potential and lithium-ion diffusion coefficient of graphite. To the best of our knowledge, this is the first systematic study on the lithium-ion diffusion coefficient of graphite as a function of lithium-ion concentration and potential.

\section{Materials and Methods}

A commercial graphite electrode sheet was provided from LIBEST (Daejeon, Korea). This graphite electrode sheet was composed of $91 \mathrm{wt} . \%$ graphite (See the Figure S1) as the active material, $1 \mathrm{wt} . \%$ Super-P carbon black as a conductive additive, and $8 \mathrm{wt} . \%$ polyvinylidene fluoride as a binder polymer. The electrode was cast on a copper foil $(10 \mu \mathrm{m}$ thickness), dried, roll pressed, and then punched into discs $1.5 \mathrm{~cm}$ in diameter to obtain a mixture loading level of $8.68 \mathrm{mg} / \mathrm{cm}^{2}$ with a thickness of $100 \mu \mathrm{m}$ (the overall thickness of the graphite electrode sheet was $110 \mu \mathrm{m}$ ). The 2032-type coin cells were then assembled with a prepared electrode disc as the cathode and a lithium metal foil as the anode using $1 \mathrm{M}$ lithium hexafluorophosphate in ethylene carbonate (EC) and ethyl methyl carbonate (EMC) as the electrolyte (EC/EMC, 3:7 w/w).

Electrochemical characterization of the coin cell was performed using a battery test system (Land Instruments, CT2001A). The coin cell was first tested at $27^{\circ} \mathrm{C}$ in order to investigate the specific capacity and Coulombic efficiency. GITT experiments were conducted to determine the quasi-equilibrium open circuit potential (QOCP) and lithiumion diffusion coefficients as functions of the lithium-ion concentration in graphite. For the electrochemical experiments, the upper and lower cut-off potentials were set to 1.5 and $0.06 \mathrm{~V}$ vs. lithium metal, respectively. For the GITT experiments, a series of current pulses were imposed on the cell for $1200 \mathrm{~s}$, after which the relaxation potentials of the cell were measured for $2400 \mathrm{~s}$ when no current was applied. Figure 1a shows GITT experimental condition during charge at $0.05 \mathrm{C}$. Figure $1 \mathrm{~b}$ shows representative GITT curves under charging conditions of $0.05 \mathrm{C}$. When a positive current pulse was applied, the potential first increased quickly — corresponding to the electrical internal resistance of the electrode-and subsequently increased slowly due to electrochemical lithium-ion deintercalation upon galvanostatic charging. After reaching a certain cell potential, due to electrical internal resistance, the potential instantaneously dropped, after which it slowly decreased until reaching equilibrium at the QOCP. When a negative current pulse was applied, the opposite held true. The diffusion coefficient $(D)$ can be calculated at each step as follows:

$$
D=\frac{4}{\pi \tau}\left(\frac{n V}{S}\right)^{2}\left(\frac{\Delta E_{s}}{\Delta E_{t}}\right)^{2}, \tau<\frac{L^{2}}{D}
$$


where $\tau$ is the duration of the current pulse (s), $n$ is the number of moles (mol) of the electrode, $V$ is the molar volume $\left(\mathrm{cm}^{3} / \mathrm{mol}\right)$ of the electrode, $L$ is the thickness of the electrode, and $S$ is the apparent electrode area $\left(\mathrm{cm}^{2}\right)[22,23]$. As shown in Figure $1 \mathrm{~b}, \Delta E_{t}$ is the potential change for the charge/discharge current pulse, while $\Delta E_{s}$ is the steadystate voltage change after eliminating the IR drop originating from the electrical internal resistance.

(a)

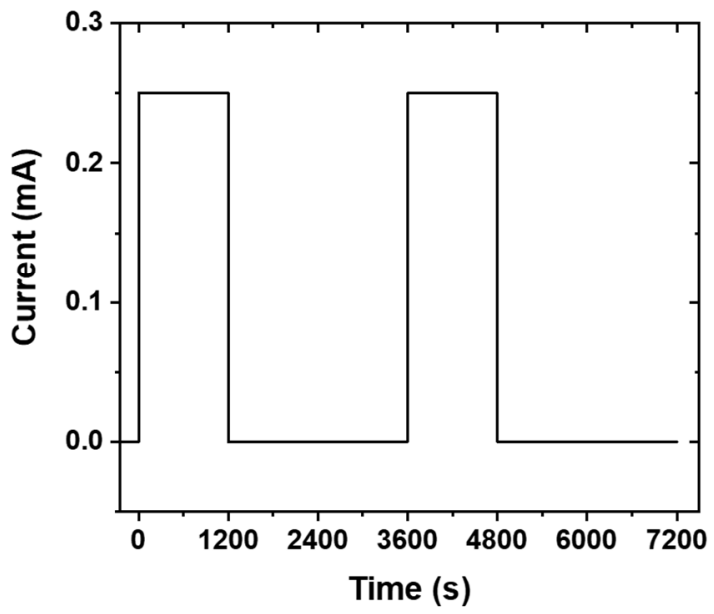

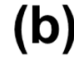

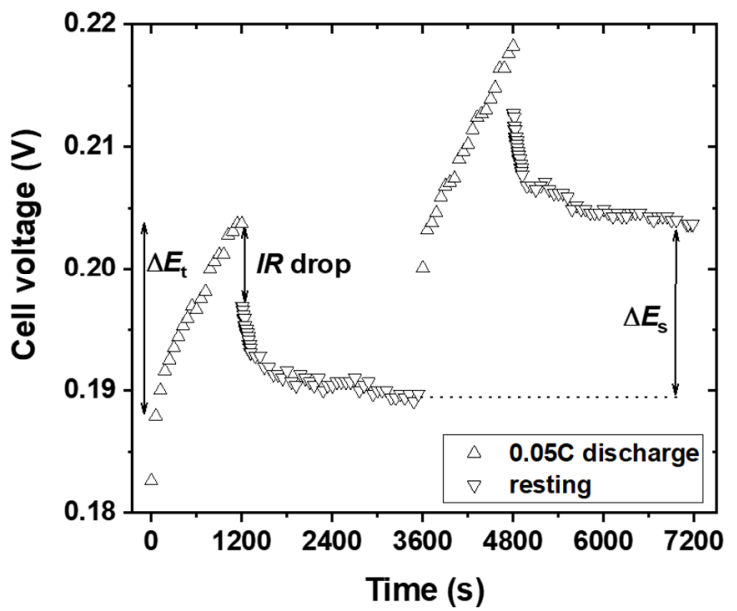

Figure 1. (a) Galvanostatic intermittent titration technique (GITT) experimental conditions during charge at 0.05C. (b) Corresponding variations in potential during the $0.05 \mathrm{C}$ charging current pulses and relaxation periods, where $\Delta E_{t}$ is the overall change in potentials during the current pulses after subtracting the IR drop and $\Delta E_{S}$ is the change in steady-state potential.

\section{Results and Discussion}

Figure 2a shows the galvanostatic charge-discharge curves as a function of charging Crate $(0.2 \mathrm{C}, 0.5 \mathrm{C}, 1 \mathrm{C}, 2 \mathrm{C}$, and $5 \mathrm{C})$ when the discharging $\mathrm{C}$-rate was fixed at $0.2 \mathrm{C}$. At $0.2 \mathrm{C}$, the highest charge capacity and Coulombic efficiency were $365 \mathrm{mAh} / \mathrm{g}$ and $99.5 \%$, respectively (Figure 2b). Both charge capacity and Coulombic efficiency decreased with increasing Crate due to sluggish lithium intercalation kinetics. Therefore, among the $\mathrm{C}$-rates analyzed, $0.2 \mathrm{C}$ was the highest that could be used to perform GITT measurements to determine the diffusion coefficient for reversible lithium-ion intercalation/deintercalation into graphite, with respect to specific capacity and Coulombic efficiency. Since the GITT measurements included a series of current pulses followed by a relaxation period, the optimal C-rate for GITT measurements could be different from that used in the galvanostatic charge/discharge experiments. Therefore, three different $C$-rates $(0.2 C, 0.05 C$, and $0.01 C)$ were used in the GITT measurements and were examined to extract the quasi open circuit potential and the diffusion coefficient.

As shown in Figure 3, GITT measurements were performed at $0.2 \mathrm{C}, 0.05 \mathrm{C}$, and $0.01 \mathrm{C}$ charge/discharge rates. The potential change during the current pulse and relaxation process at $0.01 \mathrm{C}$ was insignificant compared to those obtained at $0.2 \mathrm{C}$ and $0.05 \mathrm{C}$ rates. This suggests that the duration of both the current pulse and the relaxation process must increase substantially to observe a significant potential change at $0.01 \mathrm{C}$. By contrast, the GITT curves at $0.2 \mathrm{C}$ and $0.05 \mathrm{C}$ displayed a change in the potential for both the current pulse and relaxation process, which originated from lithium-ion intercalation/deintercalation and ion redistribution after intercalation in graphite, respectively. According to the GITT theory $[22,23]$, the change in potential during the current pulse must exhibit linear behavior as a function of the square root of time. Figure 4 shows the potential change of the current pulse as a function of the square root of time at $0.05 \mathrm{C}$ charge/discharge rate, which exhibits linear behavior with $\mathrm{R}^{2}>0.95$. Furthermore, weak linear behavior of the potential change of the current pulse was observed at $0.2 \mathrm{C}$ and $0.01 \mathrm{C}$ charge/discharge 
rates (Figures S2 and S3), particularly for the charge pulse $\left(0.61<\mathrm{R}^{2}<0.98\right)$. This suggests that the optimum charge/discharge rate was $0.05 \mathrm{C}$ for the GITT investigation.
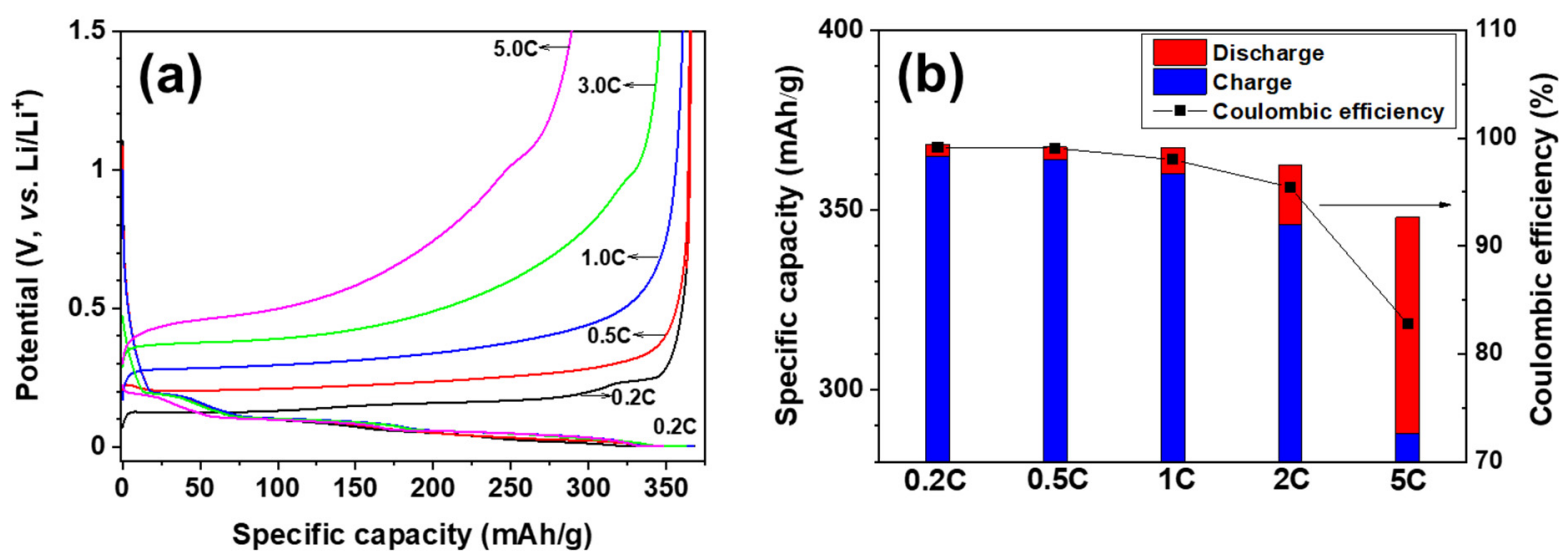

Figure 2. (a) Rate capability measured at $0.2 \mathrm{C}$ for discharging and at various rates for charging. (b) Summary of specific capacity and Coulombic efficiency.

(a)

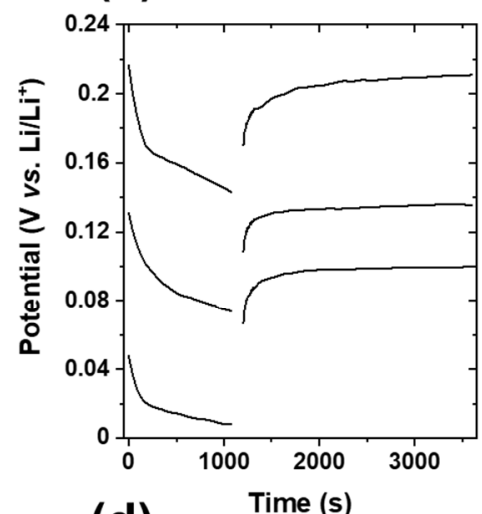

(d)

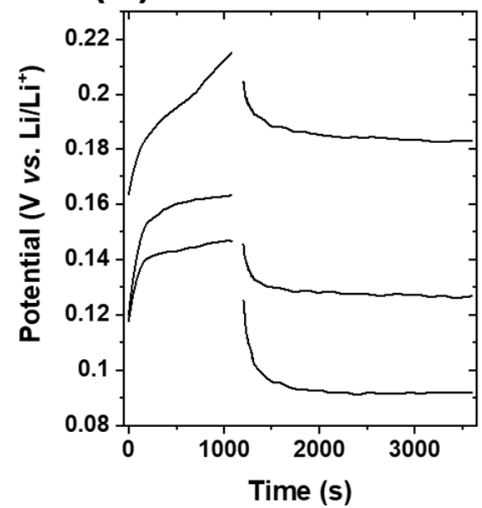

(b)

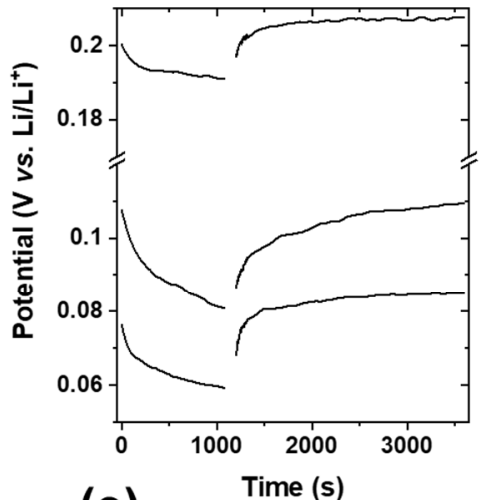

(e)

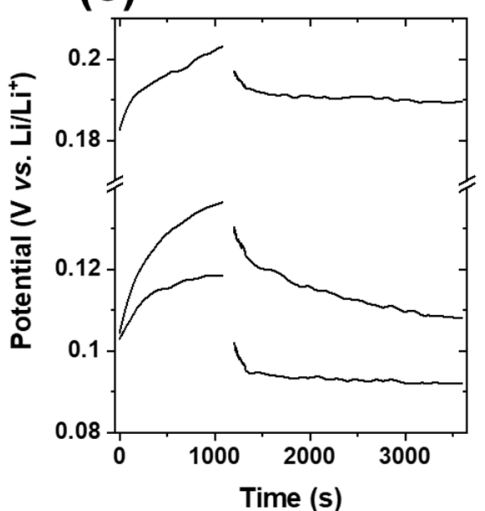

(c)
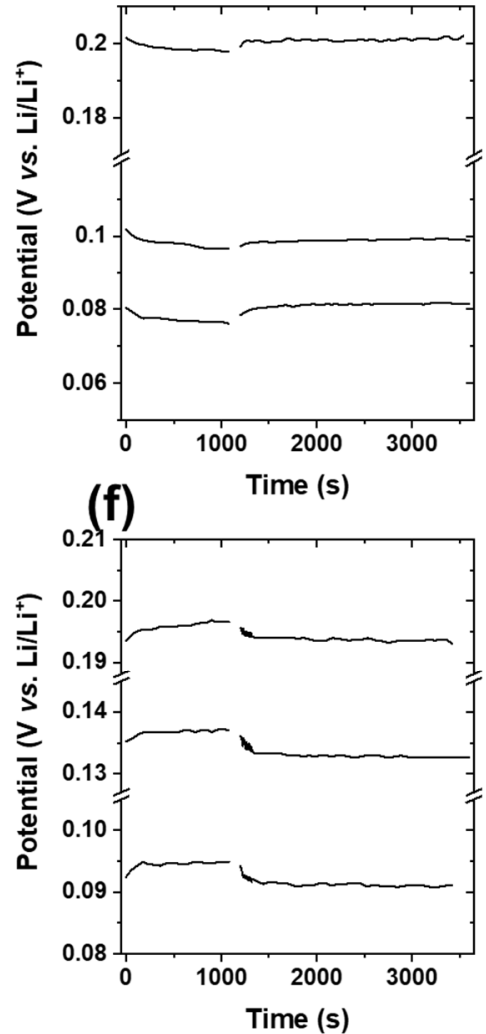

Figure 3. Variations in potential during current pulses for $1200 \mathrm{~s}$ and a relaxation period of $2400 \mathrm{~s}$ at the three, representative discharge (top)/charge (bottom) C-rates: (a,d) 0.2C, (b,e) 0.05C, and (c,f) $0.01 \mathrm{C}$. 
(a)
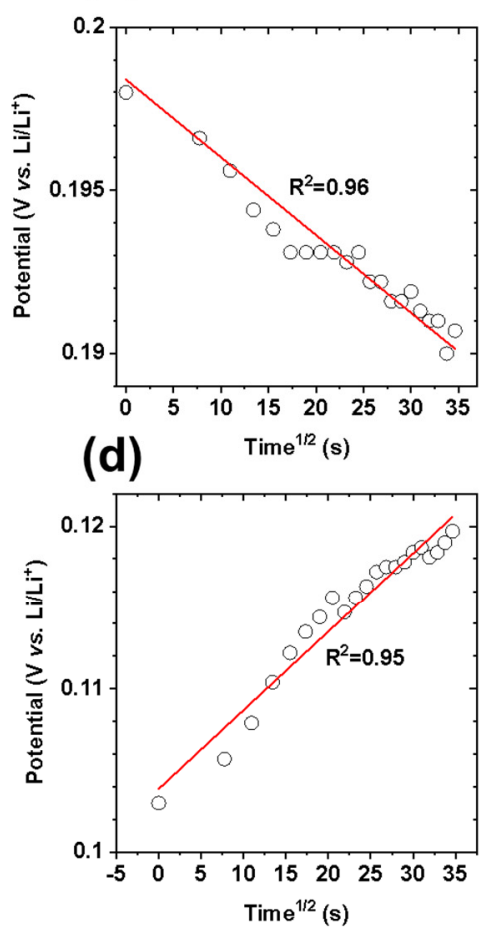

(b)
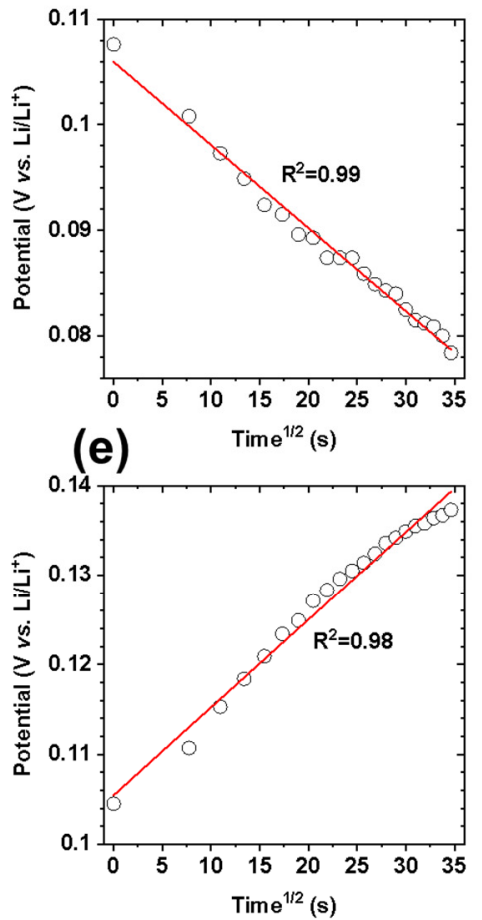

(c)
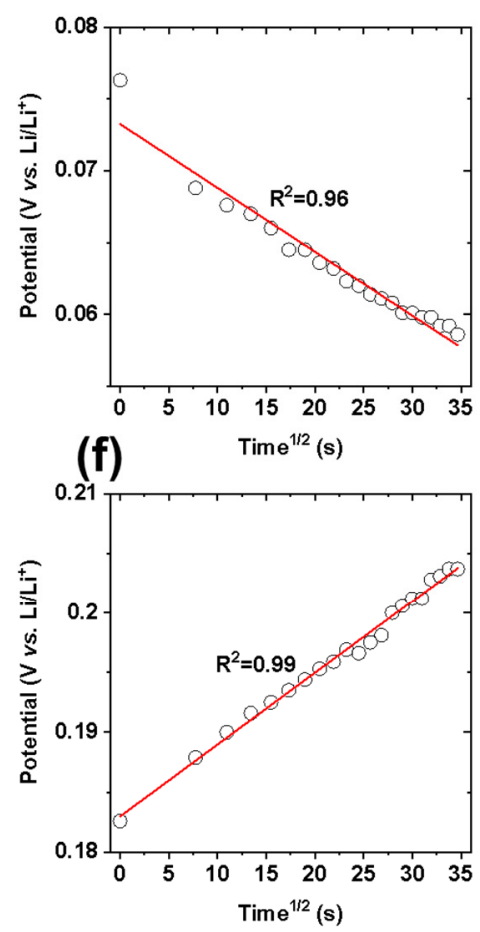

Figure 4. Changes in potential during the current pulses as a function of time ${ }^{1 / 2}$ during three representative discharge (top, $(\mathbf{a}-\mathbf{c})$ ) and three charge (bottom, $(\mathbf{d}-\mathbf{f})$ ) processes at a rate of $0.05 \mathrm{C}$. The linear fitting line and $\mathrm{R}^{2}$ value of the linear regression are also displayed. Diffusion is rate-limiting for the electrochemical ion intercalation/deintercalation process when the potential change during the current pulse exhibits linear behavior with respect to the square root of time; this is because the diffusion coefficient determined by the GITT is based on Fick's law.

The GITT measurement curves and QOCP values during charge/discharge at $0.05 \mathrm{C}$ rate are shown in Figure 5. QOCP is also plotted as a function of lithium concentration in graphite $\left(\mathrm{x}\right.$ in $\left.\mathrm{LiC}_{6 / \mathrm{x}}\right)$, displaying three different plateaus. Low-level hysteresis was observed between charging and discharging with $\mathrm{x}<0.08$, as this low concentration of intercalated lithium resulted in random intercalation of lithium ion in graphite. Even though a large hysteresis between lithium insertion and removal on QOCP graphite was observed previously [24-26], no distinct hysteresis was found when $x \geq 0.08$, suggesting that a rate of $0.05 \mathrm{C}$ is sufficiently slow to investigate lithium intercalation/deintercalation processes.

Three transients of the QOCP were observed at $1.0-0.22 \mathrm{~V}, 0.2-0.1 \mathrm{~V}$, and $0.1-0.08 \mathrm{~V}$, which arose from disordered lithium ions intercalated in graphite and were attributed to a significant increase in the intercalation reaction entropy and considerable change of the QOCP [24]. The plateaus are located at approximately $0.22,0.12$, and $0.08 \mathrm{~V}$ for both charge/discharge QOCPs. These distinct plateaus confirm that reversible lithium intercalation/deintercalation occurs because the chemical potential of the lithium ion in coexisting phases is equal with respect to the cell potential [27]. In the first plateau at $\sim 0.22 \mathrm{~V}(0.08 \leq \mathrm{x} \leq 0.17)$, the formation of a $\mathrm{LiC}_{36}$ phase (Stage 4$)$ occurs according to $\mathrm{LiC}_{72}+\mathrm{Li}^{+}+\mathrm{e}^{-} \leftrightarrow 2 \mathrm{LiC}_{36}$. The second plateau at $\sim 0.12 \mathrm{~V}(0.25 \leq \mathrm{x} \leq 0.50)$ is attributed to the formation of a $\mathrm{LiC}_{12}$ phase (Stage 2) following $\mathrm{LiC}_{24}+\mathrm{Li}^{+}+\mathrm{e}^{-} \leftrightarrow 2 \mathrm{LiC}_{12}$. The third plateau at $\sim 0.08 \mathrm{~V}(\mathrm{x} \geq 0.55)$ represents the reversible phase transition between $\mathrm{LiC}_{12}$ and $\mathrm{LiC}_{6}$ (Stage 1, $\mathrm{LiC}_{12}+\mathrm{Li}^{+}+\mathrm{e}^{-} \leftrightarrow 2 \mathrm{LiC}_{6}$ ). 
(a)

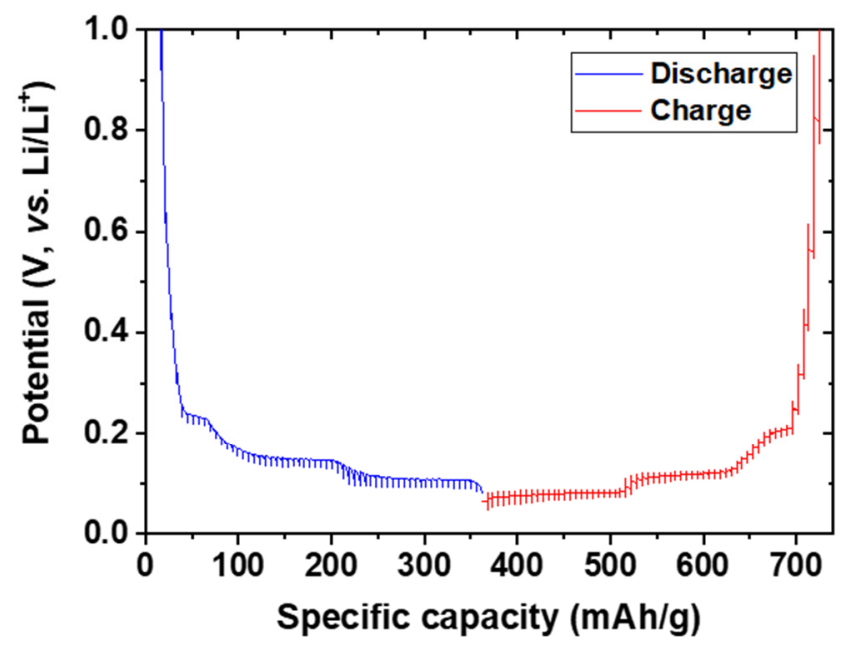

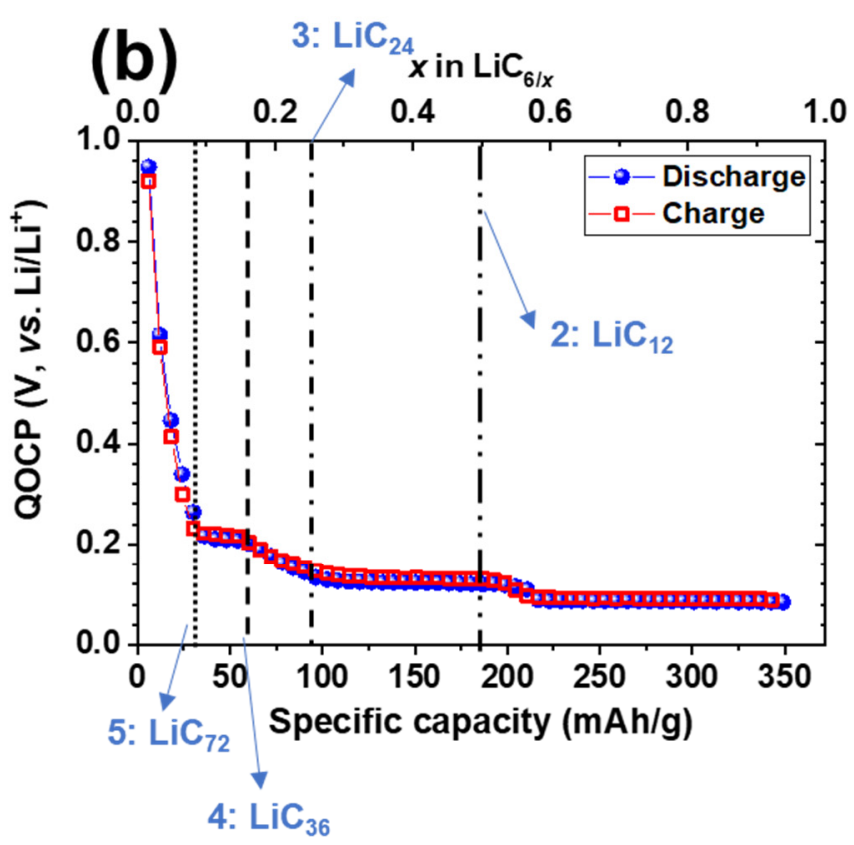

Figure 5. (a) GITT curves and (b) quasi-equilibrium open circuit potential (QOCP) values during charge/discharge at a rate of $0.05 \mathrm{C}$.

The diffusion coefficient $(D)$ of graphite during charge/discharge at a rate of $0.05 \mathrm{C}$ as a function of lithium concentration $\left(\mathrm{x}\right.$ in $\left.\mathrm{LiC}_{6 / \mathrm{x}}\right)$ was investigated (Figure 6). The trends of diffusion coefficients between charge and discharge, which increase with increasing lithium concentration $\left(x\right.$ in $\left.\mathrm{LiC}_{6 / \mathrm{x}}\right)$, are nearly identical. When $\mathrm{x}<0.16$, the diffusion coefficient is $\sim 10^{-11} \mathrm{~cm}^{2} / \mathrm{s}$; because the d-spacing of graphite undergoes an insignificant change from $3.36 \AA$ to $3.39 \AA$ upon lithium-ion intercalation [28], a high overpotential for both the insertion and removal of lithium ions occurs. In situ synchrotron X-ray diffraction results confirmed that the symmetry of the $\left(\begin{array}{lll}0 & 0\end{array}\right)$ peak of graphite exhibited higher symmetry upon lithium-ion intercalation due to the strong repulsion between intercalated lithium ions $[25,27,28]$, resulting in an increased diffusion coefficient. In the range of $0.16 \leq x \leq 0.2$, the diffusion coefficient substantially increased approximately 10 fold to $\sim 2 \times 10^{-10} \mathrm{~cm}^{2} / \mathrm{s}$, since the d-spacing of graphite increased significantly from $3.39 \AA$ to $3.49 \AA$, thus providing sufficient space for lithium-ion diffusion in conjunction with the formation of the $\mathrm{LiC}_{36}$ phase [28]. The diffusion coefficient decreased slightly to approximately $8 \times 10^{-11} \mathrm{~cm}^{2} / \mathrm{s}$ in the $0.2 \leq \mathrm{x} \leq 0.25$ range due to formation of $\mathrm{LiC}_{24}$, which is in good agreement with previous X-ray diffraction studies [25,27]; lithium ions in $\mathrm{LiC}_{24}$ are intercalated in a more compact manner than in the $\mathrm{LiC}_{36}$ phase. When $0.25 \leq \mathrm{x} \leq 0.5$, the diffusion coefficient was found to increase again to $\sim 2 \times 10^{-10} \mathrm{~cm}^{2} / \mathrm{s}$ due to the phase transition from $\mathrm{LiC}_{24}$ to $\mathrm{LiC}_{12}$ [29]. During this transition, lithium ions were sufficiently intercalated into graphite and available for diffusion from the edge to the basal plane, which is in good agreement with the high entropy associated with the charge/discharge process [24,25]. At $x \geq 0.5$, the diffusion coefficient remained at approximately $10^{-10} \mathrm{~cm}^{2} / \mathrm{s}$ but exhibited a sharp drop for both charge/discharge curves at $x=0.6$. This sudden decrease at $x=0.6$ is associated with the formation of a superdense $\mathrm{LiC}_{12}$ intermediate phases, such as $\mathrm{Li}_{7} \mathrm{C}_{24}$ or $\mathrm{Li}_{11} \mathrm{C}_{24}$ [25], acting as nucleation sites for the formation of $\mathrm{LiC}_{6}$ as observed in in situ $\mathrm{X}$-ray diffraction. This is because the presence of intermediate phases leads to a lithium concentration gradient between the surface and interior of graphite particles, which hinders lithium-ion diffusion. 

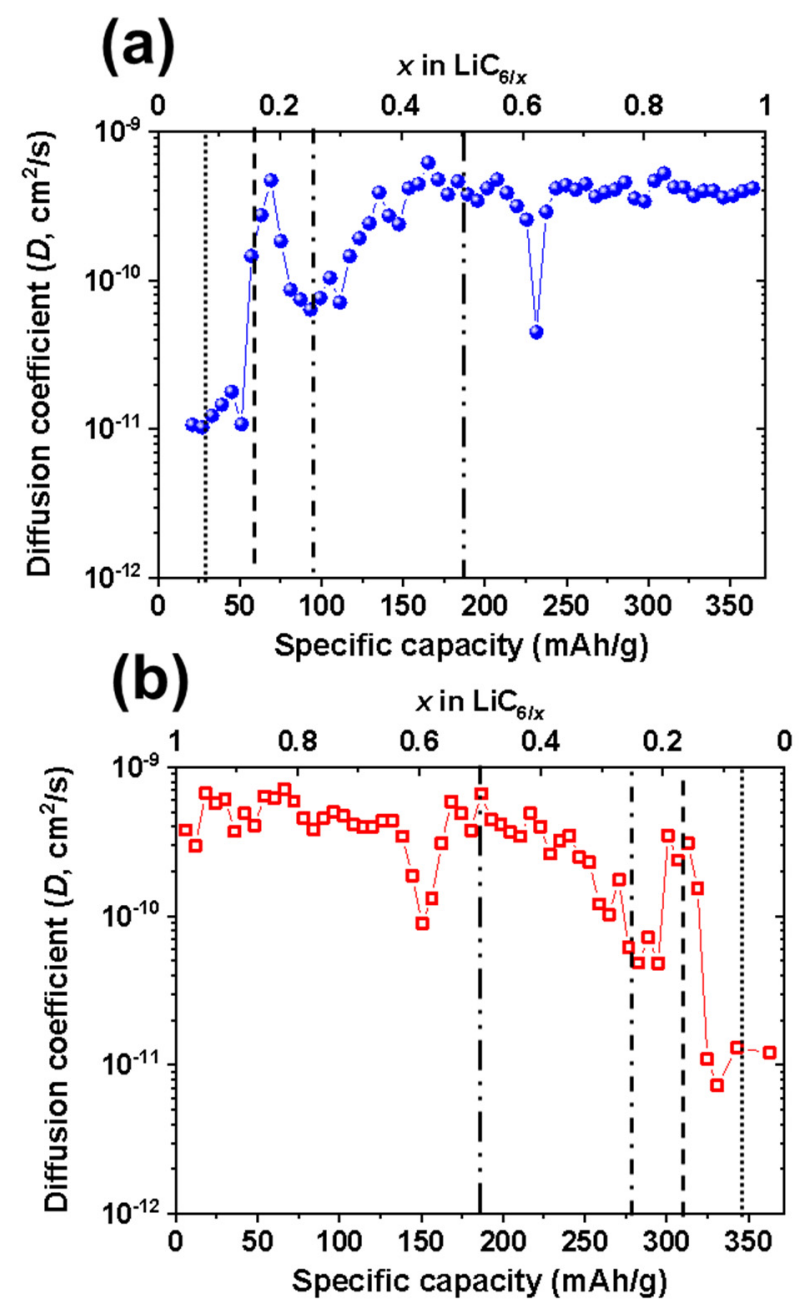

Figure 6. Calculated diffusion coefficient $(D)$ of graphite from the GITT for discharge (top, (a)) / charge (bottom, (b)) at a rate of $0.05 \mathrm{C}$ as a function of lithium concentration $\left(\mathrm{x}\right.$ in $\left.\mathrm{LiC}_{6 / \mathrm{x}}\right)$.

The diffusion coefficients of lithium-ion intercalation in graphite as a function of specific capacity $\left(x\right.$ in $\mathrm{LiC}_{6 / \mathrm{x}}$ ) and potential (vs. $\mathrm{Li}^{+} / \mathrm{Li}$ ) from different EIS studies are compared in Figure 7. Only a single diffusion coefficient value of $4 \times 10^{-8} \mathrm{~cm}^{2} / \mathrm{s}$ was previously reported using the GITT with a charge current of $0.2 \mathrm{~mA}$ [15], which is similar to this study. Recently, diffusion coefficient values of graphite in the range of $1 \times 10^{-13}$ to $2 \times 10^{-11} \mathrm{~cm}^{2} / \mathrm{s}$ determined from the GITT have been reported using relatively rapid C-rates from $0.2 \mathrm{C}$ to $5 \mathrm{C}$ [16]. However, lithium-ion diffusion coefficients of graphite as functions of specific capacity and potential have not yet been reported using the GITT. In fact, most reported lithium-ion diffusion coefficients as functions of specific capacity and potential are obtained from EIS [8-14] and potentiostatic intermittent titration technique measurements [17]. Even though discrepancies between lithium-ion diffusion coefficients could arise from differences in the structure of graphite particles, electrode sheet composition, and analysis techniques, the lithium-ion diffusion coefficient obtained from this study is in reasonable agreement with the results from Levi and Aurbach [8] and Ong and Yang [9] as a function of $x$ in $\mathrm{LiC}_{6 / \mathrm{x}}$, and with those of Yang et al. [13] as a function of potential. It has been demonstrated that the GITT enables the direct and reliable determination of the lithium-ion diffusion coefficient of graphite when the lithium-ion intercalation/deintercalation reaction occurs reversibly. 


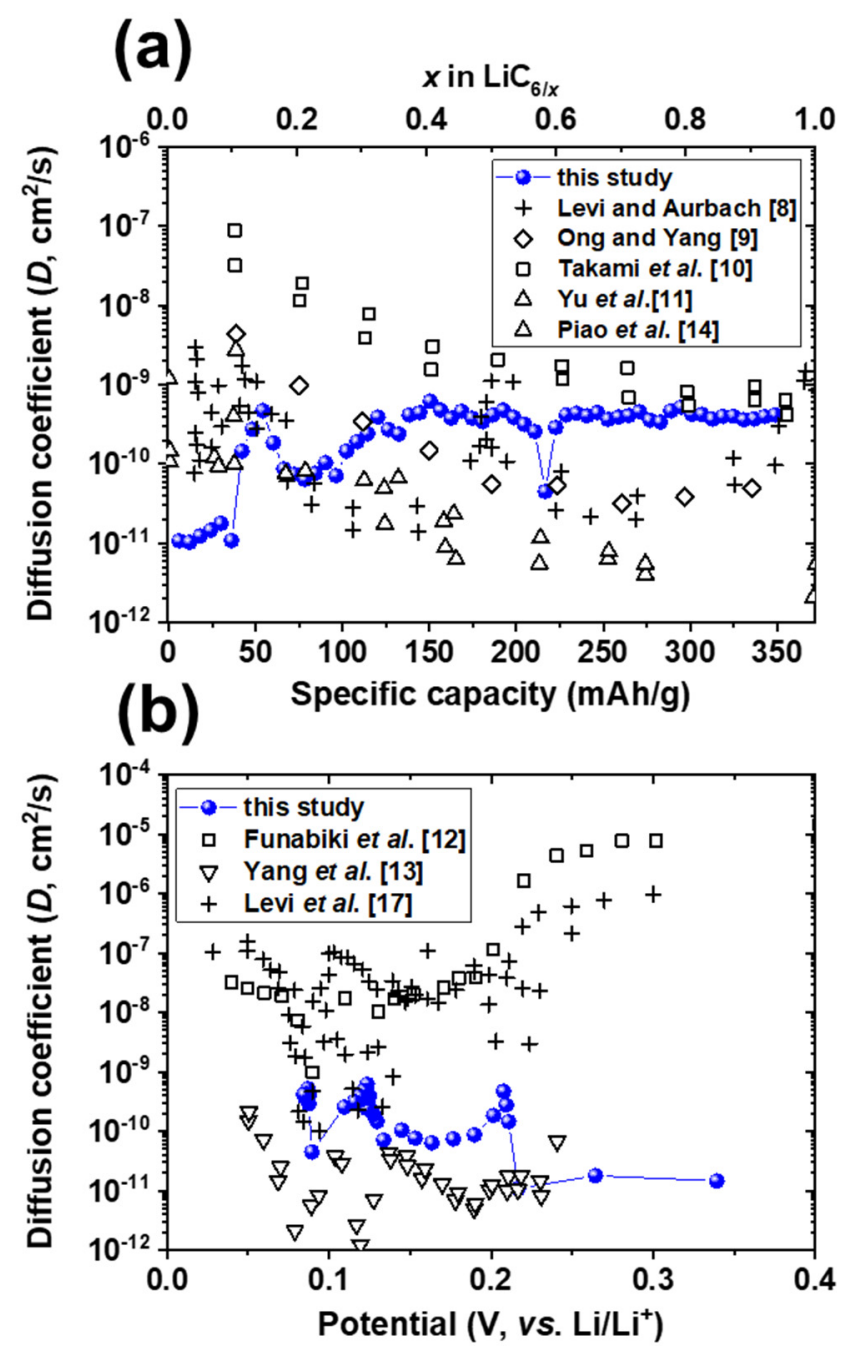

Figure 7. Survey of experimental and literature diffusion coefficient $(D)$ values for lithium-ion intercalation in graphite as functions of (a) specific capacity ( $\mathrm{x}$ in $\mathrm{LiC}_{6 / \mathrm{x}}$ ) and (b) potential (vs. $\left.\mathrm{Li}^{+} / \mathrm{Li}\right)$.

\section{Conclusions}

We investigated the quasi-equilibrium open circuit potential and lithium-ion diffusion coefficient of a graphite electrode by employing the galvanostatic intermittent titration technique as a function of intercalated lithium-ion concentration $\left(x\right.$ in $\left.\mathrm{LiC}_{6 / \mathrm{x}}\right)$ and potential. We determined that the optimum charge/discharge rate was $0.05 \mathrm{C}$ for investigation of the quasi-equilibrium open circuit potential and lithium-ion diffusion coefficient of graphite. Furthermore, three distinct plateaus were identified from the quasi-equilibrium open circuit potential curves at approximately $0.22,0.12$, and $0.08 \mathrm{~V}$; the first plateau at $\sim 0.22 \mathrm{~V}$ $(0.08 \leq \mathrm{x} \leq 0.17)$ corresponds to the phase transition from $\mathrm{LiC}_{72}$ to $\mathrm{LiC}_{36}$, the second plateau at $\sim 0.12 \mathrm{~V}(0.25 \leq \mathrm{x} \leq 0.50)$ is related to the phase transition from $\mathrm{LiC}_{24}$ to $\mathrm{LiC}_{12}$, and the third plateau at $\sim 0.08 \mathrm{~V}(\mathrm{x} \geq 0.55)$ corresponds to the phase transition from $\mathrm{LiC}_{12}$ to $\mathrm{LiC}_{6}$. Finally, the calculated diffusion coefficient values from the galvanostatic intermittent titration technique were in the range of $1 \times 10^{-11} \mathrm{~cm}^{2} / \mathrm{s}$ to $4 \times 10^{-10} \mathrm{~cm}^{2} / \mathrm{s}$, showing fair agreement with previous results obtained using electrochemical impedance spectroscopy. We believe that once reversible electrochemical intercalation/deintercalation conditions are established, the galvanostatic intermittent titration technique can be universally applied as a powerful tool to determine the ion diffusion coefficients of graphite-based electrodes. 
Supplementary Materials: The following are available online at https://www.mdpi.com/article/10 .3390/ma14164683/s1: Figure S1: X-ray diffraction pattern and secondary electron microscopy image of graphite powder; Figure S2: Change in potential during the current pulse with time $\mathrm{e}^{1 / 2}$, and the linear fitting line, and $\mathrm{R}^{2}$ of the linear regression during discharge (top)/charge (bottom) at a rate of 0.2C; and Figure S3: Change in potential during the current pulse with time $\mathrm{e}^{1 / 2}$, and the linear fitting line, and $\mathrm{R}^{2}$ of the linear regression during discharge (top)/charge (bottom) at a rate of $0.01 \mathrm{C}$.

Author Contributions: Conceptualization, J.H.P. and C.-Y.Y.; investigation, J.H.P., H.Y., Y.C., and C.-Y.Y.; writing-original draft preparation, J.H.P., H.Y., Y.C., and C.-Y.Y.; writing-review and editing, J.H.P., H.Y., Y.C., and C.-Y.Y.; funding acquisition, C.-Y.Y. All authors have read and agreed to the published version of the manuscript.

Funding: This research was supported by Research Funds of Mokpo National University in 2020.

Institutional Review Board Statement: Not applicable.

Informed Consent Statement: Not applicable.

Data Availability Statement: All data included in this study are available upon request by contact with the corresponding author.

Conflicts of Interest: The authors declare no conflict of interest.

\section{References}

1. Yang, Z.; Zhang, J.; Kintner-Meyer, M.C.W.; Lu, X.; Choi, D.; Lemmon, J.P.; Liu, J. Electrochemical Energy Storage for Green Grid. Chem. Rev. 2011, 111, 3577-3613. [CrossRef]

2. Zubi, G.; Dufo-López, R.; Carvalho, M.; Pasaoglu, G. The lithium-ion battery: State of the art and future perspectives. Renew. Sustain. Energy Rev. 2018, 89, 292-308. [CrossRef]

3. Asenbauer, J.; Eisenmann, T.; Kuenzel, M.; Kazzazi, A.; Chen, Z.; Bresser, D. The success story of graphite as a lithium-ion anode material-fundamentals, remaining challenges, and recent developments including silicon (oxide) composites. Sustain. Energy Fuels 2020, 4, 5387-5416. [CrossRef]

4. Liu, Y.; Zhu, Y.; Cui, Y. Challenges and opportunities towards fast-charging battery materials. Nat. Energy 2019, 4, 540-550. [CrossRef]

5. Chen, X.; Li, Y.; Wang, J. Enhanced Electrochemical Performance of $\mathrm{LiFePO}_{4}$ Originating from the Synergistic Effect of ZnO and C Co-Modification. Nanomaterials 2021, 11, 12. [CrossRef]

6. Akintola, T.; Shellikeri, A.; Akintola, T.; Zheng, J.P. The Influence of $\mathrm{Li}_{4} \mathrm{Ti}_{5} \mathrm{O}_{12}$ Preparation Method on Lithium-Ion Capacitor Performance. Batteries 2021, 7, 33. [CrossRef]

7. Zhang, Y.; Li, J.; Li, W.; Kang, D. Synthesis of One-Dimensional Mesoporous Ag Nanoparticles-Modified TiO 2 Nanofibers by Electrospinning for Lithium Ion Batteries. Materials 2019, 12, 2630. [CrossRef]

8. Levi, M.D.; Aurbach, D. Diffusion coefficients of lithium ions during intercalation into graphite derived from the simultaneous measurements and modeling of electrochemical impedance and potentiostatic intermittent titration characteristics of thin graphite electrodes. J. Phys. Chem. B 1997, 101, 4641-4647. [CrossRef]

9. Ong, T.S.; Yang, H. Symmetrical cell for electrochemical AC impedance studies of lithium intercalation into graphite. Electrochem. Solid State Lett. 2001, 4, A89. [CrossRef]

10. Takami, N.; Satoh, A.; Hara, M.; Ohsaki, T. Structural and Kinetic Characterization of Lithium Intercalation into Carbon Anodes for Secondary Lithium Batteries. J. Electrochem. Soc. 1995, 142, 371-379. [CrossRef]

11. Yu, P.; Popov, B.N.; Ritter, J.A.; White, R.E. Determination of the Lithium Ion Diffusion Coefficient in Graphite. J. Electrochem. Soc. 1999, 146, 8. [CrossRef]

12. Funabiki, A.; Inaba, M.; Ogumi, Z.; Yuasa, S.; Otsuji, J.; Tasaka, A. Impedance Study on the Electrochemical Lithium Intercalation into Natural Graphite Powder. J. Electrochem. Soc. 1998, 145, 172-178. [CrossRef]

13. Yang, H.; Bang, H.J.; Prakash, J. Evaluation of Electrochemical Interface Area and Lithium Diffusion Coefficient for a Composite Graphite Anode. J. Electrochem. Soc. 2004, 151, A1247. [CrossRef]

14. Piao, T.; Park, S.; Doh, C.; Moon, S. Intercalation of Lithium Ions into Graphite Electrodes Studied by AC Impedance Measurements. J. Electrochem. Soc. 1999, 146, 2794-2798. [CrossRef]

15. Yazami, R.; Touzain, P. A reversible graphite-lithium negative electrode for electrochemical generators. J. Power Sources 1983, 9 , 365-371. [CrossRef]

16. Dees, D.W.; Rodrigues, M.-T.F.; Kalaga, K.; Trask, S.E.; Shkrob, I.A.; Abraham, D.P.; Jansen, A.N. Apparent Increasing Lithium Diffusion Coefficient with Applied Current in Graphite. J. Electrochem. Soc. 2020, 167, 120528. [CrossRef]

17. Levi, M.D.; Markevich, E.; Aurbach, D. The effect of slow interfacial kinetics on the chronoamperometric response of composite lithiated graphite electrodes and on the calculation of the chemical diffusion coefficient of Li Ions in graphite. J. Phys. Chem. B 2005, 109, 7420-7427. [CrossRef] 
18. Persson, K.; Sethuraman, V.A.; Hardwick, L.J.; Hinuma, Y.; Meng, Y.S.; Van Der Ven, A.; Srinivasan, V.; Kostecki, R.; Ceder, G. Lithium diffusion in graphitic carbon. J. Phys. Chem. Lett. 2010, 1, 1176-1180. [CrossRef]

19. Zhu, J.; Dewi Darma, M.S.; Knapp, M.; Sørensen, D.R.; Heere, M.; Fang, Q.; Wang, X.; Dai, H.; Mereacre, L.; Senyshyn, A.; et al. Investigation of lithium-ion battery degradation mechanisms by combining differential voltage analysis and alternating current impedance. J. Power Sources 2020, 448, 227575. [CrossRef]

20. Li, W.; Rentemeister, M.; Badeda, J.; Jöst, D.; Schulte, D.; Sauer, D.U. Digital twin for battery systems: Cloud battery management system with online state-of-charge and state-of-health estimation. J. Energy Storage 2020, 30, 101557. [CrossRef]

21. Deng, C.; Lu, W. Consistent diffusivity measurement between Galvanostatic Intermittent Titration Technique and Electrochemical Impedance Spectroscopy. J. Power Sources 2020, 473, 228613. [CrossRef]

22. Weppner, W.; Huggins, R.A. Determination of the Kinetic Parameters of Mixed-Conducting Electrodes and Application to the System $\mathrm{Li}_{3} \mathrm{Sb}$. J. Electrochem. Soc. 1977, 124, 1569-1578. [CrossRef]

23. Deiss, E. Spurious chemical diffusion coefficients of $\mathrm{Li}^{+}$in electrode materials evaluated with GITT. Electrochim. Acta 2005, 50, 2927-2932. [CrossRef]

24. Allart, D.; Montaru, M.; Gualous, H. Model of Lithium Intercalation into Graphite by Potentiometric Analysis with Equilibrium and Entropy Change Curves of Graphite Electrode. J. Electrochem. Soc. 2018, 165, A380-A387. [CrossRef]

25. Yazami, R.; Reynier, Y. Thermodynamics and crystal structure anomalies in lithium-intercalated graphite. J. Power Sources 2006, 153, 312-318. [CrossRef]

26. Ohzuku, T.; Iwakoshi, Y.; Sawai, K. Formation of Lithium-Graphite Intercalation Compounds in Nonaqueous Electrolytes and Their Application as a Negative Electrode for a Lithium Ion (Shuttlecock) Cell. J. Electrochem. Soc. 1993, 140, 2490-2498. [CrossRef]

27. Dahn, J.R. Phase diagram of $\mathrm{LiC}_{6}$. Phys. Rev. B 1991, 44, 9170. [CrossRef]

28. He, H.; Huang, C.; Luo, C.W.; Liu, J.J.; Chao, Z.S. Dynamic study of Li intercalation into graphite by in situ high energy synchrotron XRD. Electrochim. Acta 2013, 92, 148-152. [CrossRef]

29. Bernardi, D.M.; Go, J.Y. Analysis of pulse and relaxation behavior in lithium-ion batteries. J. Power Sources 2011, $196,412-427$. [CrossRef] 